\title{
Drivers of Online Brand Community Value Creation: The Role of Psychological Empowerment
}

\author{
Sara H. Hsieh \\ Tunghai University \\ hchsieh@thu.edu.tw
}

\author{
Timmy H. Tseng \\ National Changhua University \\ of Education \\ timmyhtseng@gmail.com
}

\author{
Crystal T. Lee \\ Wenzhou Business College \\ Iampinkcrystal@gmail.com
}

\begin{abstract}
There is an upsurge of consumer empowerment driven by the rise of the Internet and online communities. However, the effect of psychological empowerment that may be experienced in contributing knowledge and experiences in the process of participation in online brand community has seldom been investigated. This study aims to examine the role of psychological empowerment in online brand community and its impact on value cocreation behaviors. By using PLS-SEM, the result indicate that perceived responsiveness, validation, status seeking, perceived network size, and information quality, facilitates the establishment of psychological empowerment, which in turn promotes consumers' value co-creation behaviors. Implications for researchers and practitioners are discussed.
\end{abstract}

\section{Introduction}

The diffusion of new technologies instigated a massive growth of online brand communities in the past decade, which has drawn pronounced attention among marketers and researchers [10, 41]. The web has become a central place for the creation and exchange of knowledge. Online brand communities which provide an environment where consumers can interact with other members who share common brand interest are increasingly becoming an important platform for consumers to interact and obtain information. Supported by the Internet, the connected consumers are empowered by sharing knowledge and experiences, which allows them to participate in co-creating values for the brand. Lusch and Vargo [39] posits that firms are prompted to collaborate with consumers to co-create values by seeking consumer's participation in contributing knowledge and ideas, for example Lego tapping into the brand communities to harness the innovation of consumers to enhance the Lego robotic ideas [29].
Online brand communities can provide an empowering environment where the individuals experience empowerment to participate in collective value creation that increases firm benefits.

Although some of the online brand communities successfully attract members to actively participate in contributing knowledge, exchanging brand experiences, many other online brand community member's interaction level is low. It is likely that the level of empowerment that is experienced among differential contextual environment of the online brand community may cause distinctive impact in drawing participation. Hence, the overall phenomena entails a clearer examination of what might have gone wrong for these online brand communities. How does the perceived experience generated by the contextual environmental of the online brand community create a sense of empowerment to impact on individual's intention to participate in contributing knowledge and sharing experience? To answer this question, an investigation that allow deeper understanding into the drivers of psychological empowerment in online brand community and its effect in value co-creation is crucial.

The concept of empowerment has been widely discussed in organizational disciplines [13, 51, 59]. Recently, the focus has been shifted to consumer empowerment as scholars postulated that there is an upsurge of consumer empowerment driven by the rise of the Internet and then reignited by online communities [25, 30]. Psychological empowerment manifests a psychological state that is shaped by the environment [54]. Social factors and functional dimensional factors are two important reasons why people join online brand communities. However, how the social factors and functional factors affect the development of psychological empowerment in the process of participation in online brand communities has seldom been carefully investigated. To fill the research gap, drawing from the psychological empowerment theory $[13,59]$, the objective of the present research is to examine how social and 
functional dimensional factors in the environment of online brand community facilitates psychological empowerment, which in turn enhances the intention to participate in the value co-creation behaviors. The present research is the first to examine the effects of social and functional dimensional drivers, which may facilitate the establishment of psychological empowerment in online brand communities. It thus advances the area of research on online brand community and empowerment theory.

\section{Literature review}

Empowerment theory postulates environmental factors interact with individual's cognitions, perceptions, and attitudes, to impose influences on individual behaviors [58]. Empowerment is seen as an enabling process, "enabling implies creating conditions for heightening motivation for task accomplishment through the development of a strong sense of personal efficacy" [13] (p. 474). Bandura [5] viewed the empowerment from a motivational perspective as a process whereby an individual's belief in his self-efficacy is enriched [5]. Past literatures are mostly drawn from job design studies in management literatures [32]. However, though empowerment builds from the roots of job enrichment theory, the multidimensional conceptualization of empowerment extends beyond it.

Thomas and Velthouse [54] define empowerment as an increased intrinsic motivation which delineates an individual's work role orientation. They posit that empowerment is a multifaceted construct, which encompasses four cognitions: meaning, competence, self-determination, and impact. Drawing from the definition postulated by Spreitzer [51], the present study defines psychological empowerment as individual's active motivational orientation toward value co-creation in the online brand community. The four manifested cognitions proposed by Spreitzer [51], also illustrates the characteristic of psychological empowerment in this study: Meaning indicates the value of the work goal corresponding to individual's personal goals, which illustrate a fit between the requests of a work role and a person's beliefs, values, and behaviors [9]. Competence indicates self-efficacy, the belief of an individual's ability to perform the work activities with the necessary skills [21]. This is similar to personal mastery, or effort-performance expectancy [6]. Selfdetermination indicates exhibiting the ability to make choices and instigating actions [15]. Selfdetermination illustrates an individual's autonomy to make initiations, make decisions regarding the methods adopted in work, and the continuation of work behavior and processes. Impact indicates the extent an individual's ability to make a difference to the outcomes at work [3]. Therefore, the psychological empowerment characterized by the four cognitive dimensions postulates an active orientation to the work role, where individuals not only have more control over their own work, they can possess a higher level of "voice" in influencing activities and impose impact over larger organizational matters [19].

Psychological empowerment manifests a psychological state that is shaped by the environment [54]. Thomas and Velthouse [54] underscore that the work environment can have a significant impact on the establishment of empowerment, indicating the influence of content and nature of an environment. For individuals to feel empowered, it is essential that they perceive the environment is liberating instead of constraining [15]. Spreitzer [52] delineates characteristics of the work environment that facilitates the establishment of psychological empowerment, such as perceptions of sociopolitical support, role ambiguity, and work unit climate, access to information and resources. Thus for the empowering process to unfold, it is necessary that it is perceived the barriers are uplifted and opportunities for enrichment is strengthened in the environmental scopes. The importance of individual's perceptions is highlighted as the definitions of empowerment emphasized is the belief that an individual can exert control over the decisions to be made [42]. Bandura posits that, instead of being entirely determined by the environments, individuals take an active role to perceive those environments and are hence affected by the individual's perceptions instead of the objective reality [6]. In sum, psychological empowerment manifest the ongoing ebb and flow of individual's perceptions about their environment in association with themselves. Sizable studies show support in the enabling effect of the environment to create psychological empowerment. Drawing from literatures that assert many similarities are shared between employee and consumer behaviors [8], we propose that online brand community which creates an online environment for people to interact, also create an environment where the enabling process of psychological empowerment can be fostered.

The investigation of psychological empowerment in the social media context is emerging. Li [36] examined the connection between active and passive social media use and psychological empowerment. Their findings indicate that active social media use is positively associated with psychological 
empowerment. This may be attributed by individual's awareness of their influence and collective power that may exert over others online. Amichai-Hamburger, Mckenna and Tal [1] emphasized that Internet is an empowering tool as it links individual with a wider community, where self-efficacy and experience can be enhanced. Furthermore, past studies reveal that social media facilitate consumer empowerment, which in turn produces positive outcomes for the social media. Consumers can generate content such as reviews and recommendations through online communities. This builds trust in the social media and facilitate the purchase intention of using social media platforms $[24,25]$.

\section{Theoretical framework and hypotheses}

The present research's conceptual framework explicates the central role of psychological empowerment in the participation of online brand communities, along with its antecedents and impact on behavior intention. By adopting the empowerment theory $[13,52,59]$ as the conceptual lens, the present study proposes a model and develop hypotheses. Psychological empowerment manifests a psychological state that is shaped and enabled by the environment [54]. Social factors and functional dimensional factors are two important reasons why people join online brand communities. Therefore, the social and functional dimensional driving factors and its impact on psychological empowerment in the online brand community is examined. The present study seek foundation and expands from Spreitzer [52]'s model in the work environment to provide a fresh perspective in the online brand community context. Spreitzer [52] indicates that individuals' perceptions of sociopolitical support, role ambiguity, and work unit climate, access to information, resources, and span of control facilitate the establishment of psychological empowerment. Role ambiguity and span of control in Spreitzer [52]'s work environment findings is not relevant to our social media context, thus only the essence of sociopolitical support, work unit climate and access to information and resource is adapted into our model. Given the potential for new insights in our social media context, we added factors that we felt was missing for explanation and delineate how the perceived experience affected by the online brand community environmental factors facilitates psychological empowerment, which in turn enhances consumers' value creation behaviors.

\subsection{Social related antecedents of psychological empowerment}

3.1.1. Perceived responsiveness. Online brand community provides an environment that is built upon conversation, and when individual shares information and experiences by posting a message, they anticipate to receive responses. Thus supporting this expectation by being responsive displays a sense of goodwill and kindness [46]. Spreitzer [52]'s model indicates that participation and encouragement of responsiveness in the work unit climate facilitates the sense of empowerment. Foa's [17] resource exchange theory postulates that individuals exchange six kinds of resources: love (such as showing warmth and comfort), information, status, services, money, and goods. Reciprocating behaviors in social interactions is demonstrated by the process of receiving and providing various resources. The individual who offers the resources, such as sharing information, knowledge or experience, expects to receive reciprocal support. Thus by extending resource exchange to the context of online brand community, when an individual share experience or information, whether the content is knowledge sharing, enjoyment in product usage or insightful usage experience, the individual expects some kind of response, which shows the reciprocal of social support.

In the virtual environment where facial expression and body language are absent, the sense of support to the individual posting the message is demonstrated through perceived responsiveness to the posted message. Greater responsiveness from others indicates a willingness to help other community members and increases the reciprocal nature of the community itself, displaying adherence to norms. Responsiveness can also indicate benevolence by interacting conferring to the accepted social rules. Responsiveness has been connected with an increased perception of cooperative intentions [46], an indication of kindness. Thus, the reciprocating behavior of responsiveness, where members of the online brand community display to other members when they share information and experience to the community facilitates trust among the members. Trust in online communities can be understood in the context of interpersonal relationship [48]. In the online brand community an individual does not carry a conversation with one individual, but is posting to a general audience, therefore trust is generalized at a collective group of people [46]. When trust that is developed between an individual and the group members the online brand community, it fosters closeness and the establishment of communal 
relationship. The repeated interaction, displayed through responsiveness helps the trust to evolve.

Prior research indicates that in a trusted and supportive environment where individuals are able to express their values, the sense of empowerment can be fostered [12]. According to Conger and Kanungo [13], empowerment is seen as an enabling process, where the conditions are created for heightening motivation for task accomplishment through the development of a strong sense of personal efficacy. For individuals to feel empowered, it is essential that they perceive the environment is liberating instead of constraining [15]. Previous research shows that receiving support in the work related environment is also found to exhibit direct influence on an individual sense of competence to accomplish task [47]. The perceived responsiveness provides a sense of support that is analogous to the social support that individuals receive in a work environment. Therefore, in an online brand community environment where individuals experience perceived responsiveness, it is likely that it will facilitate the establishment of psychological empowerment for individuals to participate in sharing information and experience.

\section{H1: The perceived responsiveness of the online brand} communities facilitates psychological empowerment.

3.1.2. Perceived validation. Perceived validation indicates the extent an individual feels that other community members affirm the importance of the information, knowledge and opinions that the individual shares [4]. The sense of validation provides satisfaction to the individual's need for recognition. According to Spreitzer [52]'s model in the work environment, sociopolitical support from supervisor or peer indicates validation and approval. This enhances personal sense of power and facilitates psychological empowerment. In the social media environment, when individuals participate in information and knowledge sharing online, individuals may be driven by the desire to build personal identity, establish confidence, obtain respect and confidence and make their expertise known publicly. Prior research indicates that the opportunity to receive recognition through the expression of thoughts and opinions in content creation online positively affects an individual's perceived psychological empowerment [34]. According to the theory of empowerment, the environment that provides an enabling process to the individual facilitates the psychological empowerment [59]. When the enabling process created by the environment is present, it creates increased motivation for individual to engage in task accomplishment through the development of a strong sense of personal efficacy [13]. Therefore, in an online brand community where individuals experience validation from other members, it is likely that it will facilitate personal efficacy and psychological empowerment, for individuals to share information and experience.

H2: The perceived validation of the online brand communities facilitates psychological empowerment.

3.1.3. Status seeking. Status indicates an individual's relative position in a group which is built according to esteem, prestige, or honor [7]. Thus, status seeking postulates individual engaging in activities aimed at improving one's position in a group to increase prestige and esteem [31]. Status seeking can be driven by external and internal objectives. Seeking for social and economic benefits are external objectives. While status seeking pursued for emotional reasons such as achieving ego reward, when an individual attains the desired status are internal objectives [17]. Previous research asserts that status seeking is associated with information sharing such as news sharing among social media users [33]. Status seeking in online communities is attained through the creation of reputation to enhance status and increase the sense of importance [31]. The process of achieving the sense of empowerment is motivated by power achieving goals [12]. The poweroriented goals can be seen as an objective aimed at enhancing individual's influence in the group, such as status, reputation and feeling being admired. In online brand communities, when individuals contribute information and knowledge driven by status seeking, it is likely that this facilitates the experience of empowerment in the process.

H3. Status seeking facilitates psychological empowerment in the online brand communities.

\subsection{Functional related antecedents to psychological empowerment}

3.2.1. Perceived network size. Perceived network size reflects the degree to which an individual perceives the number of members joining the online community. The benefit of online brand community is that it enables individuals to be connected with people outside of its social circles [38]. As the online brand community increases in members, the possibility of an individual to be connected to more people also increases. According to network externalities theory [28], individual's participation intention increases as the size of the community 
increases. Network externalities is defined as "the utility that a user derived from consumption of a good increases with the number of other agents consuming the good" [27] (p.424). In other words, the level of utility an individual obtains from participating in an online community depends on the amount of members joining the community. This is because as the amount of users increase, it will draw more users to join in using a particular product or service, which in turn creates more external benefits [37]. The network effects can generate a bandwagon effect as the network develops and attracts more people to join, creating a positive feedback circle. Thus, large online brand community size that allows an individual to conveniently interact with a wide scope of members, provides an access to a larger resource of knowledge and experience.

Prior research indicates that individuals who perceive that they exhibit a higher degree of access to resources shows a higher level of empowerment than individuals who perceive they have less access to resources [52]. The access to resources can increase an individual's sense of self-efficacy and control over the environmental [22]. According to empowerment theory, the environment that provides an enabling process to the individual, facilitates the establishment of psychological empowerment [59]. Therefore, in an online brand community where the perceived network size is large, it enables the individuals to tap into large resource, thus it is likely that it will facilitate the establishment of psychological empowerment. Furthermore, when the individual shares information and experience to community with a large number of participants, the message is likely to be dispersed to a wide base of audience. This enables the individual to exert greater influence over a larger group of people, which also creates a sense of empowerment for the individual.

H4: The perceived network size of the online brand communities facilitates psychological empowerment.

3.2.2. Perceived information quality. Consumers seek updated and accurate informational benefits from online communities [16]. Information quality is the perceived quality and excellence of the information provided by the online brand community. Social cognition theory posits that access to information facilitates a sense of self-efficacy [22]. In the model proposed by Spreitzer [52] in the work environment, access to information and resources facilitate psychological empowerment. Kanter [26] (p.5) asserts that for an organization to be empowering, it is crucial that "more information are available to more people at more levels through more devices". The empowerment process requires the sharing of information to enable individuals to contribute in the work environment [19]. Thus, an online brand community which provides access to high information quality and more updated information enables individual to be better informed, is a more empowering environment. According to theory of empowerment, the environment that provides an enabling process to the individual, facilitates the establishment of psychological empowerment [59]. The findings of Spreitzer [52] also show evidence that the enabling effect of the environment facilitates psychological empowerment. In the online brand community where individuals perceives higher information quality, the enabling process is likely to facilitate the establishment of psychological empowerment for individuals.

H5: The information quality of the online brand communities facilitates psychological empowerment.

\subsection{Psychological empowerment and consumers' value creation behaviors}

Empowerment is seen as an enabling process and results in an enhanced intrinsic motivation to accomplish task [13, 54]. Empowerment links individual strength and competencies with voluntary mutual help in the community [43]. Furthermore, psychological empowerment has a positive effect on increasing organizational citizenship behavior [53]. When individual's psychological empowerment is enhanced it is plausible that individuals believe they have stronger impact in the online brand community. The increased belief of self-efficacy and feelings of obligation may lead to a sense of ownership to the brand community [44], which increases their intention to participate in voluntary behaviors in value creation. Viewing customers as partial employee is widely discussed in the co-creation literatures [49], where consumers voluntarily take on a more active role in affecting and promoting the brand, helping in brand use, welcoming new members. Previous studies show that consumers can assume three types of voluntary behaviors that is related to citizenship behaviors: advocacy, helping others and providing feedback [56]. Advocacy indicates individuals in the online brand community engages in the behavior of recommending and creating favorable word of mouth which promotes the online brand community. Individuals spread positive words about the online brand community [49].

Helping others asserts that individuals of the online brand community interact and actively participate in providing helpful information to other 
members. The crucial role of an online brand community is providing a platform for the exchange of knowledge and experience. Thus, it is key that brand community members are willing to assume the role of helping others. Providing helpful information increases the brand knowledge, which assists other members to solve product usage problems and helps them to make informed purchase decisions [55].

Providing feedback posits that members of the online brand community cares about the brand and provides opinions, ideas and suggestions to the brand. Psychological empowerment can be facilitated in an enabling environment [52]. When online brand community members feel the enhancement of psychological empowerment, this is likely to facilitate a trusted relationship with the brand community, where they can make proactive contributions to the online brand community. Thus, the psychological empowerment created in the environment of online brand community, is likely to facilitate consumers' value creation behaviors.

H6: Psychological empowerment in the online brand communities facilitates advocacy (H6a), helping others (H6b), and feedback (H6c).

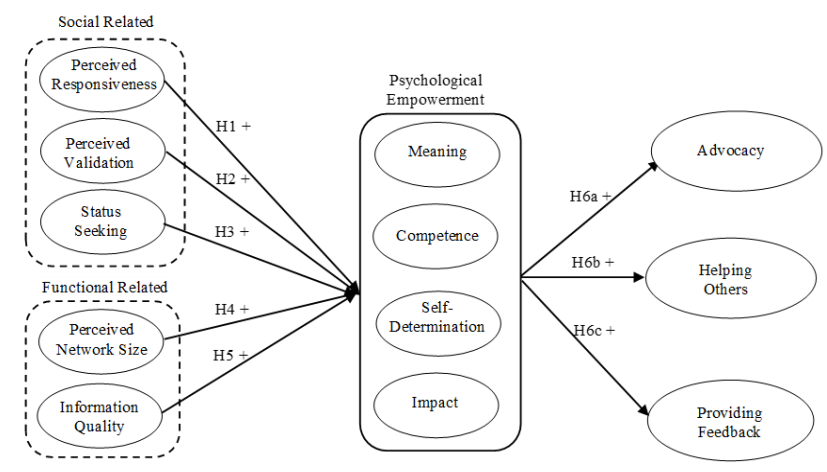

Figure 1. Conceptual Model

\section{Method}

\subsection{Sample and data collection}

The online brand communities used for this study were selected based on the following criteria. First, members are allowed to freely share contents on product ideas or customer experiences. Second, the online brand community has an adequate number of active members. Third, the online brand community was from a well-known brand. The following online brand communities were selected: LEGO, My Starbucks Idea, Niketalk, SONY Playstation, Harley
Davidson Owners Group, Strikes of Kings. The selected online brand communities include different product categories of toys, video games, online games, sportswear, motorbike, and coffee.

A questionnaire link was posted on Amazon Mturk to collect data. Members in the above online brand communities were recruited. 315 data were obtained. Respondents with no experience interacting with other community members or with incomplete answers are excluded. A total of 272 usable data were used for the analysis. Of all the respondents, $62.5 \%$ were male. $85.7 \%$ are "21-40 year old". Most of the respondents used the online brand community 1-6 times a week (52.2\%) and had the membership for more than 6 months $(56.2 \%)$. Of all the online brand communities, $51.1 \%$ were "consumer-dominated" while $48.9 \%$ were "company-dominated".

\subsection{Measures}

All the measures are adapted from established scales to suit the context of online brand communities. The items for measuring perceived responsiveness are adapted from Ridings, Gefen, and Arinze [46]. Status seeking is measured referring to items used by Li [35]. Validation is measured referring to the items from Baldus et al. [4]. Perceived network size is measured referring to the items used by Chih-Chien et al. [14]. The items for measuring information quality are adapted from Mathwick et al. [40]. The items for measuring psychological empowerment is adapted from Spreitzer [51]. Psychological empowerment is a second order construct that has four sub-dimensions of meaning, impact, selfefficacy, and self-determination. Advocacy, helping others, and providing feedback are each measured referring to the items used by Yi and Gong [57]. All of the item responses used five-point Likert scales. All the constructs are measured using three items except validation, which is measured using four items.

\subsection{Analytical methods}

Partial least square structural equation modeling (PLS-SEM) was used to analyze the data. Following procedures recommended by Anderson and Gerbing [2], this study conducted the two-stage approach using SmartPLS 3.0. The first step is to examine the measurement model and assess reliability, convergent validity, and discriminant validity. The second step is to test the hypotheses using structural equation modeling. PLS-SEM uses a nonparametric bootstrap procedure to test the statistical significance of coefficients. This study adopted 5000 bootstrap samples as recommended by Hair et al. [23] (p. 149). 


\section{Results}

\subsection{Measurement model}

All the constructs had acceptable reliability. The alpha coefficients and CR estimates for perceived responsiveness $(\alpha=0.77, \mathrm{CR}=0.87)$, status seeking $(\alpha=0.75, \mathrm{CR}=0.86)$, perceived network size $(\alpha=$ $0.70, \mathrm{CR}=0.84)$, information quality $(\alpha=0.74, \mathrm{CR}=$ 0.85), validation $(\alpha=0.79, \quad \mathrm{CR}=0.86)$, empowerment $(\alpha=0.83, \mathrm{CR}=0.89)$, advocacy $(\alpha=$ $0.78, \mathrm{CR}=0.87)$, helping others $(\alpha=0.72, \mathrm{CR}=$ $0.84)$, and providing feedback $(\alpha=0.78, \mathrm{CR}=0.87)$ are all greater than 0.7 [22] (p. 122). First-order and second- order constructs are all significantly converged $(\mathrm{p}<0.001)$. The factor loadings are between 0.74-0.89, indicating acceptable indicator reliability [23] (p. 122). From Table 1, the correlations among components of psychological empowerment are sufficiently high to justify the use of the second-order structure. From Table 2, the values of AVE of all constructs are greater than 0.5 [23] (p. 122) and the square root of the AVE estimate of each construct is greater than the correlation of the specific construct with any of the other constructs [23] (p. 116). Therefore, both convergent validity and discriminant validity are achieved.

Table 1. Correlation Matrix of the Components of Psychological Empowerment

\begin{tabular}{|c|c|c|c|c|c|}
\hline \multicolumn{2}{|c|}{ Components } & \multirow{2}{*}{$\begin{array}{l}1 \\
1\end{array}$} & \multirow[t]{2}{*}{2} & \multirow[t]{2}{*}{3} & \multirow[t]{2}{*}{4} \\
\hline 1. & Meaning & & & & \\
\hline 2. & Impact & 0.608 & $\mathbf{l}$ & & \\
\hline 3. & Self-Efficacy & 0.594 & 0.459 & $\mathbf{l}$ & \\
\hline 4. & Self-Determination & 0.589 & 0.374 & 0.633 & 1 \\
\hline
\end{tabular}

Table 2. Correlation Matrix and Descriptive Statistics of Constructs

\begin{tabular}{|c|c|c|c|c|c|c|c|c|c|}
\hline \\
\hline Construct & 1 & 2 & 3 & 4 & 5 & 6 & 7 & 8 & 9 \\
\hline $\begin{array}{l}\text { 1. Perceived } \\
\text { Responsiveness }\end{array}$ & 0.826 & & & & & & & & \\
\hline 2. Status Seeking & 0.641 & 0.818 & & & & & & & \\
\hline $\begin{array}{l}\text { 3. Perceived } \\
\text { Network Size }\end{array}$ & 0.619 & .0 .629 & .0 .792 & & & & & & \\
\hline $\begin{array}{l}\text { 4. Information } \\
\text { Quality }\end{array}$ & 0.541 & 0.626 & 0.585 & 0.811 & & & & & \\
\hline 5. Validation & 0.547 & 0.634 & 0.579 & .0 .741 & 0.781 & & & & \\
\hline 6. Empowerment & 0.756 & .0 .760 & 0.716 & 0.702 & 0.745 & 0.812 & & & \\
\hline 7. Advocacy & 0.562 & 0.619 & 0.675 & 0.677 & 0.679 & 0.730 & 0.834 & & \\
\hline 8. Helping Others & .0 .619 & .0 .560 & .0 .579 & .0 .540 & .0 .591 & 0.685 & 0.553 & 0.799 & \\
\hline $\begin{array}{l}\text { 9. Providing } \\
\text { Feedback }\end{array}$ & 0.593 & 0.579 & 0.629 & 0.614 & 0.647 & 0.687 & 0.627 & 0.698 & 0.832 \\
\hline Mean & 3.755 & 3.832 & 3.834 & 3.940 & 3.952 & 3.825 & 3.942 & 3.844 & 3.859 \\
\hline SD & 0.710 & 0.689 & 0.710 & .0 .669 & 0.624 & .0 .570 & 0.740 & 0.693 & 0.702 \\
\hline
\end{tabular}

Note: The values on the diagonal (in bold) are the square root of average variance extracted (AVE) estimates.

\subsection{Structural model}

The second step in validating structural model was to test the research hypotheses using bootstrapping technique in Smart PLS. All VIF values were below the threshold of 5 (i.e., 1.00 2.56), indicating that collinearity among the predictor constructs is not severe [23] (p. 194).

The results are shown in Figure 2. Perceived responsiveness $(\beta=0.31, p<0.001)$, validation $(\beta=0.26$, $\mathrm{p}<0.001)$, status seeking $(\beta=0.23, \mathrm{p}<0.001)$, and perceived network size $(\beta=0.18, p<0.01)$ positively influence empowerment. Information quality has a positive marginal effect on empowerment $(\beta=0.10$, $\mathrm{p}<0.06)$. Empowerment has positive effects on advocacy $(\beta=0.73, p<0.001)$, helping others $(\beta=0.69$, $\mathrm{p}<0.001)$, and providing feedback $(\beta=0.69, \mathrm{p}<0.001)$. Hence, all hypotheses are supported.

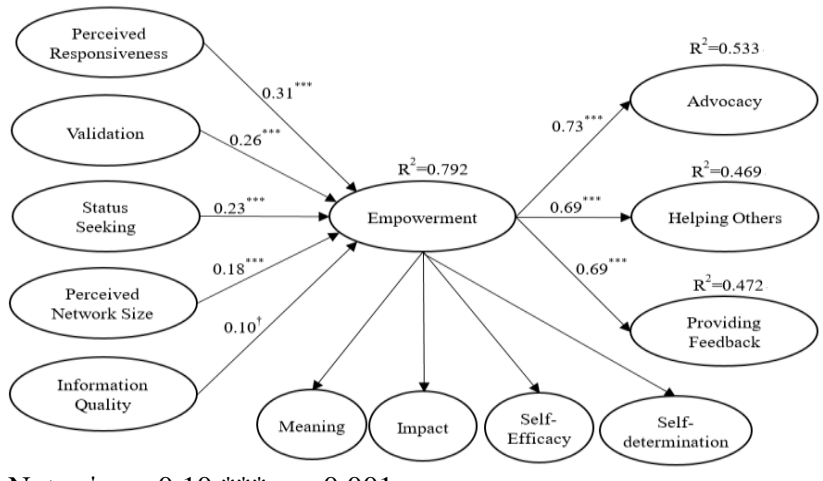

Note: $\uparrow \mathrm{p}<0.10 * * * \mathrm{p}<0.001$

Figure 2. PLS Analysis of Results

\section{Discussion}

\subsection{Theoretical implications}

This research develops a conceptual model that investigates the driving factors of psychological empowerment and its impact on value co-creation behaviors in online brand community. The findings of the results revealed that perceived responsiveness, status seeking, validation, perceived network size, and information quality, facilitates the establishment of psychological empowerment, which in turns promotes consumers' value creation behaviors of advocacy, helping others, and providing feedback. Hence, the results of this study contributes academically by exemplifying the important role of 
consumer empowerment in generating consumers' value co-creation behaviors.

This research contributes by illuminating the social and functional antecedents of empowerment in the context of online brand communities. Past studies focus on the functional antecedents such as system characteristics, tool support [20]; infrastructure characteristics, such as openness of infrastructure architecture and infrastructure interaction design [30]. The results of this study are in line with [20, 30] by indicating the importance of functional perspective of the online communities, yet we further contribute to reveal that network size and information quality which indicates access to larger resource also drives participation in online communities. Furthermore, the present study advances understanding by illuminating social aspect of online brand communities plays a crucial role in the consumers' empowerment process. This is consistent with the findings in the workplace context where sociopolitical support is a key driver of empowerment [50].

This research contributes by indicating that empowerment facilitates value creation behaviors of consumers. Past studies focused on the firms' outcomes. For instance, Füller et al. [20] revealed that perceived empowerment positively influences consumers' intention of future participation in the virtual NPD tasks. This study differs from past studies by focusing on broader outcomes including providing feedback to firms, helping other members in the online brand community, and advocating others to join the online brand community. Thus, the outcome of consumer empowerment is not restricted to firm outcome but also includes outcomes related to other community members.

The results indicated that the effect of information quality on empowerment is marginally significant while status seeking and validation are the two main drivers of empowerment. The possible reason may be attributed to the fact that the respondents of this study are members that actively participate in contributing and sharing information in the online brand communities. Online brand community members can be divided into active members and lurkers [11, 45]. Active members are more knowledgeable and constantly share their opinion on various issues while lurkers tend to be passive and learn from the shared contents from other members [45]. Thus for these active members, the information quality provided by other members in driving empowerment is relatively less important as they tend to be already knowledgeable and experienced. For these people, status seeking and validation has a stronger effect in driving a sense of empowerment.

\subsection{Managerial implications}

Among all the predictors, perceived
responsiveness is the strongest predictor to empowerment. Hence, practitioners should invest more resource in improving perceived responsiveness. For company-dominated online brand communities, practitioners can enhance members' perception of responsiveness by assigning an online customer service agent. Specifically, community members who have questions about products and services can live chat with an online customer service agent on the online brand community and the agent must respond to members' problems promptly. If the agent is offline, members are allowed to leave messages and the agent should answer members' questions within a specified time limit. Alternatively, practitioners can introduce a recommendation system to facilitate interaction and responsiveness between members. The recommendation system can match an individual's post content with other members' previous post content, and the system will remind and draw member's attention to be aware of the newly related posts. In this way, the responsiveness within the online brand community can be facilitated.

The findings from our study indicates that status seeking has a positive effect on empowerment. As such, practitioners should put more resource to stimulate the feeling of social status among community members. For instance, members who actively contribute to the online brand community by sharing knowledge to the focal brand and other community members can be rewarded by some contribution points. In turn, members can use contribution points to exchange for badges or trophies that can easily be seen by other community members, which can strengthen the psychological feeling of social status. Furthermore, these badges and trophies can have different levels such as gold, silver, bronze, iron. Thus members with higher level of badges can show their high social status to others.

Additionally, the research results show that validation facilitates psychological empowerment. Hence, practitioners can design devices to enhance members' perception that their posts are recognized and validated by other members. For example, practitioners can introduce an "I agree with you button" next to members' post. When community members see a post that they agree, they can press the "I agree with you" button to make that member feel recognized. Furthermore, practitioners can set up a threshold for the number of validation button pressed. If a given post surpasses the threshold, it will be featured in the front page of the online brand 
communities, and this should makes all contributors to the post feel psychologically recognized.

The results showed that empowerment is facilitated by perceived network size. Practitioners can enhance the perception of the network size among members by using pop-up messages, to show new members entering the online brand community. For instance, when members log onto the online brand community, a message pops out to indicate how many new members joined today, the total number of community members of this online brand community, and how many friends and relatives of the focal members are currently online. This can provide community members a sense of perceived critical mass that facilitates a sense of empowerment.

\section{Limitations and future studies}

This study investigates members that actively participate in online brand communities using a cross-sectional survey. Future research can address the cross-sectional limitations of the present study by further adopting a longitudinal investigation of psychological empowerment in online brand communities.

\section{References}

[1] Y. Amichai-Hamburger, K.Y. McKenna, and S.A. Tal, "E-Empowerment: Empowerment by the Internet", Computers in Human Behavior, vol. 24(5), pp. 1776-1789, 2008.

[2] J.C. Anderson and D.W. Gerbing, "Structural Equation Modeling in Practice: A Review and Recommended TwoStep Approach", Psychological Bulletin, vol. 103(3), pp. 411-423, 1988.

[3] B.E., Ashforth, "The Experience of Powerlessness in Organizations", Organizational Behavior and Human Decision Processes, vol. 43(2), pp. 207-242, 1989.

[4] B.J. Baldus, C. Voorhees, and R. Calantone, "Online Brand Community Engagement: Scale Development and Validation", Journal of Business Research, vol. 68(5), pp. 978-985, 2015.

[5] A. Bandura, Social Foundations of Thought and Action: A Social-Cognitive View. Englewood Cliffs, NJ: PrenticeHall, 1986.

[6] A. Bandura, "Human Agency in Social Cognitive Theory", American Psychologist, vol. 44(9), pp.1175-1184, 1989.

[7] J. Berger, B.P. Cohen, and M. Zelditch Jr, "Status Characteristics and Social Interaction", American Sociological Review, vol. 37(3), pp. 241-255, 1972.

[8] L.A. Bettencourt, A.L. Ostrom, S.W. Brown, and R.I. Roundtree, "Client Co-Production in Knowledge-Intensive Business Services", California Management Review, vol. 44(4), pp. 100-128, 2002.
[9] A.P. Brief and W.R. Nord, Meanings of Occupational Work. Lexington: Lexington Books, 1990.

[10] R.J. Brodie, A. Ilic, B. Juric, and L. Hollebeek, "Consumer Engagement in A Virtual Brand Community: An Exploratory Analysis", Journal of Business Research, vol. 66(1), pp. 105-114, 2013

[11] G. Burnett, "Information Exchange in Virtual Communities: A Typology", Available: http://www.informationr.net/ir/5-4/paper82.html, 2000.

[12] L.B. Cattaneo and A.R. Chapman, "The Process of Empowerment: A Model for Use in Research and Practice", American Psychologist, vol. 65(7), pp. 646-659, 2010.

[13] J.A. Conger and R.N. Kanungo, "The Empowerment Process: Integrating Theory and Practice", Academy of Management Review, vol. 13(3), pp. 471-482, 1988.

[14] W. Chih-Chien, Y. Hsu, and W. Fang, "Acceptance of Technology with Network Externalities: An Empirical Study of Internet Instant Messaging Services", JITTA: Journal of Information Technology Theory and Application, vol. 6(4), pp. 15-28, 2005.

[15] E.L. Deci, J.P. Connell and R.M. Ryan, "SelfDetermination in A Work Organization", Journal of Applied Psychology, vol. 74(4), pp. 580-590, 1989.

[16] U.M. Dholakia, V. Blazevic, C. Wiertz, and R. Algesheimer, "Communal Service Delivery: How Customers Benefit from Participation in Firm-Hosted Virtual P3 Communities", Journal of Service Research, vol. 12(2), pp. 208-226, 2009.

[17] R. Emerson, "Power-Dependence Relations", American Sociological Review, vol. 27(1), pp. 31-40, 1962.

[18] U.G. Foa, "Interpersonal and Economic Resources", Science, vol. 171(3969), pp. 345-351, 1971.

[19] R.C. Ford and M.D. Fottler, "Empowerment: A Matter of Degree", The Academy of Management Executive, vol. 9(3), pp. 21-29, 1995.

[20] J. Füller, H. Mühlbacher, K. Matzler, and G. Jawecki (2009), "Consumer Empowerment through Internet-Based Co-Creation", Journal of Management Information Systems, vol. 26(3), pp. 71-102, 2009.

[21] M.E. Gist, "Self-Efficacy: Implications for Organizational Behavior and Human Resource Management", Academy of Management Review, vol. 12(3), pp. 472-485, 1987.

[22] M.E. Gist and T.R. Mitchell, "Self-Efficacy: A Theoretical Analysis of its Determinants and Malleability", Academy of Management Review, vol. 17(2), pp. 183-211, 1992.

[23] J.F. Hair Jr, G.T.M. Hult, C. Ringle, and M. Sarstedt, A Primer on Partial Least Squares Structural Equation Modeling (PLS-SEM), 2nd Edition. Los Angeles: Sage Publications, 2016.

[24] M.N. Hajli, "A Study of the Impact of Social Media on Consumers", International Journal of Market Research, vol. 56(3), pp. 387-404, 2014.

[25] N. Hajli, "Social Commerce Constructs and Consumer's Intention to Buy", International Journal of Information Management, vol. 35(2), pp. 183-191, 2015.

[26] R.M. Kanter, "Empowering People to Act on Ideas", Executive Excellence, February, pp. 5-6, 1986. 
[27] M.L. Katz and C. Shapiro, "Network Externalities, Competition, and Compatibility", The American Economic Review, vol. 75(3), pp. 424-440, 1985.

[28] M.L. Katz and C. Shapiro, "Technology Adoption in the Presence of Network Externalities", Journal of Political Economy, vol. 94(4), pp. 822-841, 1986.

[29] B. Koerner, "Geeks in Toyland", Wired, February, pp. 104-112, 150, 2006.

[30] L.I. Labrecque, J. vor dem Esche, C. Mathwick, T.P. Novak, and C.F. Hofacker, "Consumer Power: Evolution in the Digital Age", Journal of Interactive Marketing, vol. 27(4), pp. 257-269, 2013.

[31] J. Lampel and A. Bhalla, "The Role of Status Seeking in Online Communities: Giving the Gift of Experience", Journal of Computer-Mediated Communication, vol. 12(2), pp. 434-455, 2007.

[32] C.R. Leana, "Power Relinquishment versus Power Sharing: Theoretical Clarification and Empirical Comparison of Delegation and Participation", Journal of Applied Psychology, vol. 72(2), pp. 228-233, 1987.

[33] C.S. Lee and L. Ma, "News Sharing in Social Media: The Effect of Gratifications and Prior Experience", Computers in Human Behavior, vol. 28(2), pp. 331-339, 2012.

[34] L. Leung, "User-Generated Content on the Internet: An Examination of Gratifications, Civic Engagement and Psychological Empowerment", New Media \& Society, vol. 11(8), pp. 1327-1347, 2009.

[35] D.C. Li, "Online Social Network Acceptance: A Social Perspective", Internet Research, vol. 21(5), pp. 562580, 2011.

[36] Z. Li, "Psychological Empowerment on Social Media: Who are the Empowered Users?", Public Relations Review, vol. 42(1), pp. 49-59, 2016.

[37] C.P. Lin and A. Bhattacherjee, "Elucidating Individual Intention to Use Interactive Information Technologies: The Role of Network Externalities", International Journal of Electronic Commerce, vol. 13(1), pp. 85-108, 2008.

[38] K.Y. Lin and H.P. Lu, "Intention to Continue Using Facebook Fan Pages from the Perspective of Social Capital Theory", Cyberpsychology, Behavior, and Social Networking, vol. 14(10), pp. 565-570, 2011.

[39] R.F. Lusch and S.L. Vargo, "Service-Dominant Logic: Reactions, Reflections and Refinements", Marketing Theory, vol. 6(3), pp. 281-288, 2006.

[40] C. Mathwick, C. Wiertz, and K. De Ruyter, "Social Capital Production in A Virtual P3 Community", Journal of Consumer Research, vol. 34(6), pp. 832-849, 2008.

[41] S. Nambisan and R.A. Baron, "Interactions in Virtual Customer Environments: Implications for Product Support and Customer Relationship Management", Journal of Interactive Marketing, vol. 21(2), pp. 42-62, 2007.

[42] L.E. Parker and R.H. Price, "Empowered Managers and Empowered Workers: The Effects of Managerial Support and Managerial Perceived Control on Workers' Sense of Control over Decision Making", Human Relations, vol. 47(8), pp. 911-928, 1994.

[43] D.D. Perkins and M.A. Zimmerman, "Empowerment Theory, Research, and Application", American Journal of Community Psychology, vol. 23(5), pp. 569-579, 1995.
[44] J.L. Pierce, T. Kostova, and K.T. Dirks, "Toward A Theory of Psychological Ownership in Organizations", Academy of Management Review, vol. 26(2), pp. 298-310, 2001.

[45] J. Preece, B. Nonnecke, and D. Andrews, "The Top Five Reasons for Lurking: Improving Community Experiences for Everyone", Computers in Human Behavior, vol. 20(2), pp. 201-223, 2004.

[46] C.M. Ridings, D. Gefen, and B. Arinze, "Some Antecedents and Effects of Trust in Virtual Communities", The Journal of Strategic Information Systems, vol. 11(3), pp. 271-295, 2002.

[47] T.L. Robbins, M.D. Crino, and L.D. Fredendall, "An Integrative Model of the Empowerment Process", Human Resource Management Review, vol. 12(3), pp. 419-443, 2002.

[48] J.B. Rotter, "Generalized Expectancies for Interpersonal Trust”, American Psychologist, vol. 26(5), pp. 443-452, 1971.

[49] H.J. Schau, A.M. Muñiz Jr, and E.J. Arnould, "How Brand Community Practices Create Value", Journal of Marketing, vol. 73(5), pp. 30-51, 2009.

[50] S.E. Seibert, G. Wang, and S.H. Courtright, "Antecedents and Consequences of Psychological and Team Empowerment in Organizations: A Meta-Analytic Review", Journal of Applied Psychology, vol. 96(5), pp. 981-1003, 2011.

[51] G.M. Spreitzer, "Psychological Empowerment in the Workplace: Dimensions, Measurement, Validation", Academy of Management Journal, vol. 38(5), pp. 14421465, 1995.

[52] G.M. Spreitzer, "Social Structural Characteristics of Psychological Empowerment", Academy of Management Journal, vol. 39(2), pp. 483-504, 1996.

[53] D. Wat and M.A. Shaffer, "Equity and Relationship Quality Influences on Organizational Citizenship Behaviors: The Mediating Role of Trust in the Supervisor and Empowerment", Personnel Review, vol. 34(4), pp. 406-422, 2005.

[54] K.W. Thomas and B.A. Velthouse, "Cognitive Elements of Empowerment: An "Interpretive" Model of Intrinsic Task Motivation", Academy of Management Review, vol. 15(4), pp. 666-681, 1990.

[55] C. Wiertz and K. de Ruyter, "Beyond the Call of Duty: Why Customers Contribute to Firm-Hosted Commercial Online Communities", Organization Studies, vol. 28(3), pp. 347-376, 2007.

[56] H.R. Yen, S.H.Y. Hsu, and C.Y. Huang (2011), "Good Soldiers on the Web: Understanding the Drivers of Participation in Online Communities of Consumption", International Journal of Electronic Commerce, vol. 15(4), pp. 89-120, 2011.

[57] Y. Yi and T. Gong, "Customer Value Co-Creation Behaviour: Scale Development and Validation", Journal of Business Research, vol. 66(9), pp. 1279-1284, 2012.

[58] B.J. Zimmerman, "Self-Efficacy: An Essential Motive to Learn", Contemporary Educational Psychology, vol. 25(1), pp. 82-91, 2000.

[59] M.A. Zimmerman, "Psychological Empowerment: Issues and Illustrations", American Journal of Community Psychology, vol. 23(5), pp. 581-599, 1995. 